\title{
Pilar Gómez Bedate, Las aguas del río, Prólogo de José Corredor-Matheos, Ediciones Olifante, Colección "Papeles de Trasmoz", Zaragoza, 2011, 80 pp.
}

Desde que Pilar Gómez Bedate publicó su primer libro de poemas, Las Peregrinaciones, en la pequeña y heroica editorial conquense El Toro de Barro, fundada y comandada por el no menos heroico sacerdotepoeta Carlos de la Rica, hasta que ha aparecido su segundo, Las aguas del río, han transcurrido nada menos que cuarenta y cinco años. A lo largo de su larga, rigurosa y a la vez jocunda trayectoria, en la esforzada labor de Pilar Gómez Bedate destacan sus atinadas interpretaciones y comentarios analíticos de la poesía española de todos los tiempos, especialmente la que atañe al siglo XX y, estrechando más el cerco, la que surge en la segunda mirad del siglo pasado; esto por un lado y, por otro, sus valorados acercamientos sobre la literatura universal (Sthendal, Simbolismo, Modernismo), sus trabajos de historiografía literaria así como sus esmeradas traducciones, tanto de textos poéticos como de textos en prosa, escritos por altos autores del panorama literario mundial, como Mallarmé, Bocaccio o Primo Levi. Colaboradora también en la fecunda singladura creativa y organizativa de su marido Ángel Crespo, fiel compañera y aliada en los incesantes menesteres intelectuales de este gran creador y trabajador, es autora también de inmejorables ediciones póstumas de Crespo, dando a conocer nuevas entregas del aquilatado poeta, traductor y ensayista desde que el gran vate manchego dejó este mundo en diciembre de 1995. La difusión, por tanto, de Pilar Gómez Bedate como poeta (aunque algunas revistas punteras y volúmenes colectivos han ofrecido algunas muestras de su quehacer poético) quedó ensombrecida por sus empeños de divulgación de la buena literatura y también, por qué no decirlo, por la potente fogosidad literario-temperamental de Ángel Crespo. Y ella siempre estaba a su lado.

Ese primer libro de Pilar Gómez Bedate, Las peregrinaciones, se sostiene en el equilibrio mantenido por contrapesados recursos: gradaciones y selectos contrastes que, de modo solemne, invisten al poema de tanta dignidad atesorando una justeza admirable y una asombrosa capacidad para desvelar el entorno que sirva de certero escenario destinado a envolver esa voz que canta en su adecuado timbre.

En Las aguas del río estas luminosas cadencias (con base en una lumínica penumbra) se mantienen, mejoradas, obviamente, por el tiempo transcurrido y la sabiduría alcanzada. Lo primero que habría que destacar en Las aguas del río es la excelente y exigente trabazón de su fábula. No olvidemos que Aristóteles dictaminaba que la esencia de un texto poético, literario (aunque él se refería concretamente a la tragedia), radica en su fábula (fábula igual a la idónea estructuración de los hechos dentro de una unidad de acción en el siempre vibrante juego entre significante y significado). Precisamente Pilar Gómez Bedate cree, cosa corroborada totalmente al término de la lectura de este libro, que en el arte poética es fundamental unir, equiparándolos, significado y expresión, eligiendo los mejores conceptos y adecuándolos en un preciso ajuste formal con el fin de conformar la mejor fábula. Juan Eduardo Cirlot, gran sabedor de que la poesía, como la lengua, es forma y no sustancia — Sausure dixit-, y consciente de que al final del proceso creador la poesía no se resuelve más que en una forma, tenía, sin embargo, la plena certeza, y así lo expresa en su artículo “Contra Mallarmé” (publicado en La Vanguardia el 16 de enero de 1969), de que "La poesía sobre todo se hace con 'ideas'; pero con ideas que son de un lado, pensamiento, de otro 'ideas técnicas', esto es, de 
técnica poética." Yo creo que este postulado está aplicado cabalmente en el libro de Gómez Bedate. Además, tengo la convicción de que las intenciones de la autora concuerdan asimismo con esta aseveración cirlotiana: "Respecto al contenido, es material poético todo cuanto se halla en relación con el hombre." En definitiva, tras leer Las aguas del río podremos asentir con gusto, respirando hondo, al tan ajustado aforismo, sintagma tan elegantemente constreñido en su enunciación latina, que expresó Horacio en su Ars poetica: "Rem tene, verba sequentur", adagio que podríamos traducir, alargándonos sobre la bellísima economía de sus cuatro palabras originarias, por "Ten bien agarrado el asunto, pues después las palabras vendrán por sí solas".

Pero ¿cómo discurre la atrayente fábula, o esa idea de pensamiento, en Las aguas del río? Sus elementos primordiales son la corriente del río Duero dinamizando el recuerdo de la vida pasada junto a Ángel Crespo que obsesiona a la autora y se expande en la evocación de la experiencia trascurrida por medio de ceñidas descripciones que atañen, bien al paso de la corriente fluvial en medio de los contornos atizados por la nostalgia, y que Pilar Gómez Bedate convierte en argumento mitológico, bien por la amorosa vivencia engrandecida al lado de su marido el poeta, incluso a la sombra de otros ríos que indefectiblemente, por suerte o por desgracia, o con mayor o menor prevalencia, remiten al Duero, señor de la infancia de Pilar transcurrida en Zamora:

El Duero es un río de cantar de gesta y de romance heroico: río duro, de muertes, venganzas y traiciones. El caudal y el fragor de sus aguas que rodea el perfil altivo de la ciudad de Zamora dejé de sentirlo mío desde que paseé contigo, en Florencia, a lo largo del Arno, sin ver en aquellas aguas otras los puñales y los venenos de su historia sino el primer encuentro de Dante con Beatriz, los destellos de su amor ideal y los primores sentimentales del dulce estilo nuevo.

Las aguas del Arno fueron nuestro bautismo de amor y cada uno de los días que pasábamos en su ciudad nos acercábamos a sus puentes para hablar de ellos por las noches, en la alcoba de la locanda, junto al Duomo, en aquella cama que era como un mundo donde nos hundíamos y nos abrazábamos con voluntad de fundirnos para siempre, protegidos por los encajes ondeantes de las cortinas y por los cristales plomados de la ventana que nos separaba de todo lo demás.

En cierto modo Gómez Bedate homenajea a Crespo en el sentido de que el poeta trasladó también a los rincones de su poética su lugar de infancia, Alcolea, un pequeño término en la provincia de Ciudad Real, donde Crespo hizo germinar una precisa visión vivencial e intelectual, escenificando en la idiosincrasia de esos naturales parajes su don creativo proyectado indeleble al futuro, ya que Alcolea, en la tan secuenciadamente profusa obra poética de Ángel Crespo, queda mitificada, hermanada con los contrastantes climas europeos, al modo de cómo queda el río Duero en la comparación afectiva y humanística que su mujer igualmente realiza.

Aristóteles escribía en su Poética que la fábula debe ofrecerse con verosimilitud, refiriéndose más que nada con ello a una necesidad de ordenamiento satisfaciendo así a la relación causa-efecto que el lector deba recibir de una manera natural, sin tener por qué apreciar el complejo entramado de la estructura exigida bajo la unísona firmeza del texto. Con esta premisa Pilar Gómez Bedate va alzando las composiciones de Las aguas del río distribuyendo a lo largo del conjunto poemas en prosa y en verso. Con marcada letra cursiva hay fragmentos que desarrollan el anclaje de la memoria del latido del Duero cubriendo el presente con una extendida gasa visceral: "La respuesta del río es la niebla. Surge de sus entrañas de limo y fango, cubre los campos, 
ciega las ventanas y se derrama por las calles de la ciudad, los ábsides románicos, los soportales de la Plaza cuyas piedras antiguas rezuman humedad." Buena parte de los poemas son abiertamente comunicativos y están dotados de un gran poder de lineal evocación, y otra buena porción los muestra altamente simbólicos, como este "Romance viejo":
A través de las rejas veo
tu túnica escarlata
y por la puerta de la muralla
los yelmos y las lanzas.
En lo alto de la torre
mi cabellera destrenzada
y en los pórticos de las iglesias
las amatistas que me dabas.
Bajo los mullidos colchones
una daga estaba clavada
y al recostarte junto a mi pecho
tu costado se ensangrentaba.

Verosimilitud no significa una reproducción fotográfica del escueto proceso de los hechos del mundo cumpliendo su estricta función, sino el artístico añadido del elemento mágico que establece una realidad total, o "entera", como le gustaba decir a Crespo, realidad inmejorablemente plasmada en el confluir del tiempo, como disponiendo de una varita mágica que unificase sus irreconciliables tres modalidades:

En Pisa, la noche se iba dibujando a sí misma sobre un paisaje sin tiempo: un paisaje azul cobalto de seda tendida, con los rojos del crepúsculo tras la dentada muralla y los mármoles blancos y labrados del baptisterio. Y con una luna que, junto a la inclinada torre, iba afirmando lentamente su contorno vaporoso. Sobre la hierba, intensamente verde, yo paseaba hablando de mis penas con nuestro Amigo, que me animaba a desecharlas. ¡Qué extraño paseo en el que tú faltabas! Entre los dos tu ausencia resplandecía y sumergía la escena en un ensueño: un Ensueño largo que nos arrastra a todos desde la Aurora hacia la Noche!

Un planteamiento que acerca este lírico tapiz, que la expresión de Las aguas del río sugiere, a los pilares estéticos de ese realismo mágico que conformó ese grupo generacional, enriquecido con las enseñanzas postistas, donde estaba ubicado Ángel Crespo en la década de los 50 del siglo XX, movimiento estudiado por Pilar Gómez Bedate con tanta asiduidad y hondura. Ese realismo mágico que, arropado en una comprensible sintaxis y en una cláusula inteligible en primera instancia, se perfuma de esencias misteriosas. 